\title{
WHO IS AND SHOULD BE A SCIENCE TEACHER
}

\section{Martin Bílek \\ Charles University, Czech Republic}

Who is and should be a Science teacher like? This seemingly multiple-time answered question, however, has not been clearly answered yet; moreover, in this case, a multi-alternative answer is required.

Ideas of an optimal characteristic of Science teacher should be defined in context of their main activity. Two alternatives are under the focus; the apparent discrepancy which has been solved in some legal documents, and the state which is frequently not unambiguous in practice.

In Alternative One, the learner is the main objective of the teacher's activities and to contribute to the learner's personal development is the main task. To develop a creative and flexible personality is the priority which requires a set of appropriate means. The learning content in Science subjects as part of general education is one of the means. This approach is applied in study programmes Teaching for Secondary Schools in general-education subjects; then, the graduate's target is to form Science literacy of the whole population (Lamanauskas, 2012).

In Alternative Two, the learning content in Science subjects, particularly the learning content of one of them, or of one part, is shifted from the category of means to the category of objectives. This approach to be ensured, teachers of so called professional (specialized, vocational) subjects are prepared. Their teaching qualification is provided in the form of further pedagogical studies conducted as a follow-up, or concurrent study with a master (mostly engineering) programme. Field specialists thus gain additional pedagogical qualification; the field specialization is essential and irretrievable for this type of teacher profession.

In Alternative One, i.e. In general education, strong preference to the content often results in suppressing the learner's personal identity and excessive misuse in the assessment of the formal content as a means of securing learners' discipline, or it can cause formalism applied in forming knowledge structures. The negative approach of a large part of the younger generation in Science education is an illegible consequence. Teacher's orientation in general education should be based on balanced subject-didactic, pedagogical-psychological and subject (field) foundations. Although the field knowledge forms the basis for creative activity of general-subject teacher conducted within the process of forming learner's personality, the way of knowledge interpretation should be in accord with a carrier of the teacher, not with the carrier of field specialist. Thus the interpretation and communication of professional information are the basis of professional/field part of teacher preparation. However, it is neither under the "roof" of the field, nor the general pedagogy (educational science) but under the subject didactics which deserves appropriate attention and space within the teacher preparation.

In latest trends, subject didactics is a synonym for Pedagogical (didactic) Content Knowledge - PCK (see e.g. Yun, 2020). In our opinion, this approach is not new but it goes for the need to create space for strengthening subject didactics (subject methodology) in teacher preparation including appropriate research and development activities. In fact, subject didactics are border disciplines dealing with problems of both the upbringing and education. They closely relate to pedagogical-psychological disciplines and the field (subject). Currently, it has not been enough to characterize subject didactics as the intersection of pedagogy and the field (subject). It is highly required to discover wider relations and connections. When designing subject didactics, knowledge and findings from other fields must be considered - gnoseology, philosophy, ethics, sociology, history, methodologies of relat- 
ing fields, psychology, informatics and others. Moreover, cooperation between the teaching of subject didactics and research should be supported, which is in close relation to the teaching as the output of teaching study programmes. Numerous institutions dealing with pre-graduate Science teacher preparation do not produce appropriate research activities in subject didactics. Thus the question appears: is it acceptable to study e.g. Chemistry, or Analytic Chemistry study programme in an institution which does not conduct any research activities in Analytic Chemistry? Is it acceptable to consider e.g. specialization in analytic chemistry as an addendum to chemistry and replace the learning content with a set of directions for work in analytic laboratory, instructions on filling records on the researched sample, sanitary and safety rules etc.? It is superfluous to continue with these "illogical"samples"; however, do they not resemble (not only in chemistry) the approach to the teaching as a profession with higher education qualification? (Bilek, 2003)

Well, what is the current state of subject didactics? "The support to theoretical and research work and the development of efficient instructional processes in all subject didactics is one of important pre-requirements of the subject-focused teacher preparation. Subject didactics should be more supported by Accreditation Commission within institution research intentions and in resort plans of pedagogical research. "The above mentioned text is part of "The call for 10 million to National programme of education development preparation"(Auth's, 1999) in the Czech Republic. Unfortunately, 20 years after, we still have not been close to meeting the requirements. A small part (units of percent) of curriculum in pre-gradual teacher preparation is devoted to subject didactics (or PCK). If standards of teacher preparation are available, they mostly form requirements on the field and pedagogy; subject didactic ones, i.e. those which directly form and develop teacher professional skills, are not under sufficient attention, or even not included at all. They are, then, acquired in teaching practice or further education. This state causes problems for novice teachers and is often a reason of the leaving the profession in experienced in-service teachers.

Let's go back to the reality of teacher preparation and our current analyses (Bílek et al., 2019). The necessity to solve inter-subject, or interdisciplinary relations is one of the appeals (Bilek, 2018). Out-of-school, community, participating or outdoor learning, these relations were identified as the core innovation in teacher preparation, not only in science subjects. Integrated instruction, integration in education, integrated view of instruction and others are under the discussion in relation to learning plans, being led either by efforts to unify the view of the nature and/ or society, or to reduce the amount of lessons within economical measures of ministries of education. The topic of integration in education is rather populistic without strong professional basis in countries where science-related subjects are taught separately. Excited discussions between supporters and rejectors of integrated instruction often fail in misunderstanding whether it means the preference of field integration, or untimely field differentiation. The core of misunderstanding mostly lies in imprecise setting of the discussion topic. There is, of course, difference, when speaking about "integration" within more widely designed Natural Science and Homeland Study as unified, integrated general-education subjects taught in $13-14 / 15$ - 16-year-old learners, or about the integration of already built knowledge from various fields in upper secondary grades of grammar and other professional schools. These differences are often forgotten, or rejected, which does not contribute to finding appropriate solutions. Thus the teacher preparation strongly bounded to the field/subject seems to be one of the barriers in teacher cooperation and reaching final consensus, and the concept of studying separate subjects within teacher preparation arises from this state. Doubled, or partially doubled subjects can be found within single subject specializations, border subjects and joint projects are missing etc., communication between departments co-operating on specializations is far from been ideal. For example, it is clear from the text of "White Book of Educational Development in the Czech Republic" (Kotásek et al., 2000) that topics on integration should have their current value. Several new features of curriculum concepts for pre-primary, primary, lower and upper secondary schools are mentioned in the White Book; they are directly connected to the discussed problems of teacher preparation:

- To support the key competency development as a tool for changing encyclopaedic concepts of education,

- To apply new forms of active instruction - mainly the project instruction - and various forms of intersubject integration, e.g. Inter-subject topics and projects, and other forms of after-school activities,

- To exploit the above-mentioned forms in implementing new fields into curricula (e.g. environmental education),

- To systematically prepare teachers for a new concept of curriculum and implementation of appropriate methods and forms of instruction,

- To include these forms and topics into the innovation and developmental programmes of the decisionmaking sphere. 
Has the time come to complementing, or rewriting the teacher preparation curriculum? Should we widen the specializations, or decrease amounts of school subjects, and reflect it in teacher preparation? Should we prepare Science teachers from the beginning of university study, or should we add several courses on teaching Science subject(s) to the study programme preparing specialists in different science and technology-oriented fields?

We have not reached consensus in answering these questions; however, latest trends in science education and relating teacher preparation strongly call for finding reasonable answers to them.

\section{References}

Auth's (1999). Teacher - Lead actor of the change (in Czech). In The call for 10 million to National programme of education development preparation (in Czech). Attachment to Newspaper "Ucitelske noviny a Verejna sprava (Teacher's Newspaper and Public Administration)", 2/2000.

Bilek, M. (2003). Chemistry didactics: Research and university instruction (in Czech). M\&V.

Bilek, M. (2018). Intercultural learning: Challenges for current science education. Journal of Baltic Science Education, $17(4), 532$ 534. https://dx.doi.org/10.33225/jbse/18.17.532

Bilek, M. et al. (2019). Teaching study programmes and forming civic and social competences (in Czech). Gaudeamus.

Kotasek, J. a kol. (2000). National programme of educational development in Czech Republic ( ${ }^{\text {nd }}$ working version in Czech). Ministry of Education. http://www.msmt.cz

Lamanauskas, V. (2012). A problem of science literacy encountered by primary school teachers and learners. Journal of Baltic Science Education, 11(4), 300 - 301. http://www.scientiasocialis.It/jbse/?q=node/264

Yun, E. (2020). Review of trends in physics education research using topic modeling. Journal of Baltic Science Education, 19(3), 388-400. https://dx.doi.org/10.33225/jbse/20.19.388 